\title{
Research on the Relationship between R\&D Investment and Cash Holdings of Enterprises
}

\author{
Yanli ZHAO \\ Wuhan Business University, Wuhan, 430056, China \\ Email: 591058771@qq.com
}

Keywords: R\&D of Enterprises; R\&D Investment; Cash Holdings

\begin{abstract}
According to previous research, we find that enterprises at home and abroad are commonly facing the challenge of financing constraints and the steady improvement of cash liquidity enables enterprises to attract necessary investment and to get rid of financial distress. Besides, the investment and outcome of $R \& D$ are related to cash holdings and are influenced by the policy of cash holdings. Nowadays, most high-tech enterprises are faced with the challenge of funds shortage and the obstruction of financing constraints due to their lack of asset mortgage. However, their current situation and the positive effect of financing constraints are ignored by most scholars at home and abroad. Thus, this paper attempts to elaborate on the current financing situation of high-tech enterprises and the positive effect of financing constraints and cash holdings on R\&D investment based on the analysis of high-tech enterprises.
\end{abstract}

\section{Introduction}

Since the reform and opening up, Chinese enterprises have been transforming their development continuously. The government has actively inspired the technical innovation and transformation of agriculture, industry and services hoping to promote the steady development of economy. [1]Nowadays, with the rapid development of science and technology, innovative capacity has become an increasingly important part of national comprehensive competitiveness. It is reported that most enterprises are at the low end of international industrial chain, namely processing and manufacturing, and they slowly develop relying on their low cost of labor force and production factors. [2]However, with the increasingly higher price of labor force a production factors in recent years, the extensive mode of production is facing an increasingly serious challenge. Hence, cash holdings has become the determining factor of enterprise's survival and development since cash is the most important resource of enterprises and is the basis of all operating activities. However, the previous research at abroad usually focuses on the influencing factors of cash holdings while ignoring the consequence of cash holdings and the relationship between cash holdings and R\&D investment. [3] And those few papers on this topic all agree that the enterprises with high cash holdings are inclined to engage in $\mathrm{R} \& \mathrm{D}$, are able to control the external financing constraints and can keep smooth investment path of R\&D. As for the previous research at home, they seldom focus on the relationship between cash holdings and R\&D investment which is sometimes referred in those papers on the relationship between financing constraints and R\&D investment. [4]Scholars at home usually hold that cash holdings can relieve financing constraints, are positively correlated with R\&D investment and show stronger investment cash flow sensitivity. Thus, this paper attempts to elaborate on $R \& D$ investment, the importance of cash holdings and the rationality of the idea "cash is all" of enterprises from the perspective of cash holdings.

\section{Definition of Relative Terms}

A. Definition of R\&D

The full name of $R \& D$ is Research \& Experiment development. The most acknowledged definitions are proposed by OECO and UNESCO. The Frascati Manual issued by OECD in 1994 defines it as the system-based innovative work aiming to rich the knowledge base involved in 
human beings, culture and society and to inspire new invention by virtue of this knowledge base.

\section{B. Definition of R\&D Investment}

$R \& D$, as the most important part of enterprise's technological innovation and the first step of innovative activities, highly depends on $R \& D$ investment. Thus, the author holds that R\&D investment is the investment of labor force and funds in $R \& D$ hoping to realize the long-term value appreciation of enterprise. [5]The major goal of $R \& D$ investment is to develop some technique or products peculiar to certain enterprises, to distinguish them from their competitors in today's competitive market and to maintain the increasingly higher profit of enterprises. Accordingly, the policy of $R \& D$ investment directly influences the operation of innovative activities and propels the development of technological innovation. From the perspective of transmission, the effect of R\&D investment includes seed effects, growth effect, cause effect and self-improve effect.

C. Definition of Cash Holdings

Cash is a medium of exchange between suppliers and buyers. That means, the exchange of goods, labor force and services are realized by it. Hence, it is very important for enterprises. Cash holdings means the amount of financial cash held by enterprises which includes cash on hand, cash in bank and short-term investment. In the daily business activities, the cash output usually doesn't synchronize with the cash input. [6]As a result, when the cash holdings are insufficient, enterprises will not be able to remain their operation and will suffer losses; when the cash holdings are sufficient, enterprises will face unnecessary wastes due to idle funds or investment in low-profit projects. Insufficient cash or too much cash will both do harm to the development of enterprise. Thus, the suitable amount of cash is very important for enterprises to deal with these two extremes. In fact, the best ways to measure the cash holdings are cost analysis mode, inventory mode and random mode. And the random mode is most widely used. The amount of cash holdings calculated in this way is higher than the other two ways and is conservative because it is based on the prediction of future demand cash and the situation of unpredictable income

\section{The Influence of Cash Holdings on Enterprise's R\&D Investment}

Previous research has proved that the use of R\&D Investment should comply with the R\&D strategy. Since the increase of R\&D Investment is one of the four major factors that lead to the increase of cash holdings, enterprises should firstly reserve cash in R\&D Investment. When the R\&D Investment changes, cash can effectively get rid of financial crisis, smooth R\&D Investment and ensure enough R\&D funds to keep enterprises run well. Thus, this paper is intended to analyze the importance of cash reserving from three aspects as follows.

A. R\&D is a Project with Continuous Investment and Sufficient Funds

The operative activities of enterprises are activities of funds' continuous recycle and processes of capital appreciation. Every part of operative activities including the purchase of raw materials and the introduction of equipment in the production link, the promotional activities and the investigation in the marketing link and the internal administrative cost needs capital investment. [7] The process of $R \& D$ Investment is also continuous and cumulative. R\&D activities including data collection, investigation of target market, design of product styles, advance of new technology, product testing and product improvement require the investment of labor force and materials. And the high-tech large-scale R\&D projects particularly have a huge appetite for funds both in the primary stage and the later stage. Enterprises should not only keep up with new products and new technology, but also prove the next generation technology. They both to some extend advance the adaptation time and development of new technology.

B. R\&D is Inclined to Raise Internal Funds Due to Its Information Asymmetry

The information asymmetry of R\&D results in the serious information conflicts between the supply and demand parties of funds, the high cost of external funds rising and accordingly the inclination of enterprises to raise internal funds. R\&D activities are able to promote the long-term development of enterprises. [7]However, they always get involved in the core of enterprises which are business secrets. As a result, banks are not willing to provide loans for enterprises because they are not clear about the inner situation of enterprises. So are most investors. Holding sufficient 
internal cash, the most liquid asset with the lowest profit, enterprises can benefit a lot mainly from two aspects. Firstly, enterprises can reduce the cost of raising external funds as well as avoid the termination of project due to funds shortage. Secondly, enterprises are capable enough to afford some unexpected links and some profitable projects and to avoid the cost of raising external funds. In short, cash holdings can meet the transactional needs, preventive needs and investment needs. Thus, enterprises are inclined to utilize internal funds firstly based on the Pecking Order Theory.

C. R\&D Needs a Stable Source of Funding Due to Its Unstable Cost of Adjustment

$\mathrm{R} \& \mathrm{D}$ is a activity combining exploration and innovation closely. The investment come of $\mathrm{R} \& \mathrm{D}$ is much higher than that of general projects. But its investment risk is also much higher than others. Thus, enterprises should be careful enough with their decisions and actions in the process of R\&D. Otherwise, they will have to cost much more labor force and materials to come back to the original development road. Besides, the high uncertainty of R\&D activities forces enterprises to be ready all the time to deal with kinds of unexpected situation in the process of $R \& D$, to avoid kinds of risks due to $R \& D$ risk and to avoid the instability of $R \& D$ due to the instability of cash liquidity. Therefore, enterprises can not only develop in a required direction and distinguish themselves from other competitors, but also increase the possibility of the success of R\&D and avoid the mid-term termination of R\&D. To avoid the high adjustment cost and high uncertainty resulting from the deviation of $R \& D$ investment, enterprises are supposed to hold sufficient cash all the time to support the whole process of $R \& D$ and to defeat other competitors.

\section{Conclusion}

Nowadays, with the demand of foreign market keeps down and the promotion of fixed-asset investment is limited, technological innovation is increasingly important. The sound combination of industry and technology is the basis and guarantee of enterprises' sound operation. In line with Chinese characteristic institutions, the reform of property and operating mechanism are continuously deepening and the $R \& D$ investment is increasingly important in listed companies especially high-tech listed companies. This paper analyses the significant influence of cash holdings on enterprise's R\&D investment as well as the positive effect of high amount of cash holdings on R\&D investment based on the theories of New Institutional Economics and accordingly propose corresponding suggestions for further technological innovation, upgrade of products and improvement of core competitiveness.

\section{Acknowledgement}

In this paper, the research was sponsored by Research on the Relationship between R\&D Investment and Cash Holdings of Enterprises---Based on Empirical Data from China's Listed, Supported by Wuhan Business School. (Project No. 2015KY001).

\section{References}

[1] The informativeness and ability of independent multi-firm directors[J] . Douglas O. Cook,Huabing (Barbara) Wang. Journal of Corporate Finance. 2010 (1)

[2] Dividend policy, creditor rights, and the agency costs of debt[J]. Paul Brockman,Emre Unlu. Journal of Financial Economics. 2009 (2)

[3] Payout policy and cash-flow uncertainty[J] . J.B. Chay,Jungwon Suh. Journal of Financial Economics. 2009 (1)

[4] Dividends for tunneling in a regulated economy: The case of China[J] . Donghua Chen,Ming Jian,Ming Xu. Pacific-Basin Finance Journal. 2008 (2)

[5] A Catering Theory of Dividends[J] . MalcolmBaker,JeffreyWurgler. The Journal of Finance. 2005 (3) 
[7] The Information Content of Share Repurchase Programs[J] . GustavoGrullon,RoniMichaely. The Journal of Finance. 2004 (2)

[7] The governance role of multiple large shareholders: evidence from the valuation of cash holdings[J]. Najah Attig, Sadok El Ghoul,Omrane Guedhami,Sorin Rizeanu. Journal of Management \& Governance. 2013 (2)

[8] Controlling shareholder, expropriations and firm's leverage decision: Evidence from Chinese Non-tradable share reform[J] . Qigui Liu,Gary Tian. Journal of Corporate Finance. 2012 (4) 